\title{
Avaliação imunofenotípica de subpopulações linfocitárias no sangue do cordão umbilical e periférico de suínos neonatos (Sus scrofa) ${ }^{1}$
}

\author{
Cesaltina C.M. Tchamo², Ivan F.C. Santos ${ }^{3 *}$, Fernanda M.C. Morato ${ }^{2}$, Roberta F. Godoy ${ }^{4}$, \\ Carmen M.L.P. Garrine ${ }^{5}$ e Áureo E. Santana ${ }^{6}$
}

\begin{abstract}
Tchamo C.C.M., Santos I.F.C., Morato F.M.C., Godoy R.F., Garrine C.L.M.P. \& Santana A.E. 2014. [Imunophenotyping avaliation of lymphocyte subsets in cord blood and peripheral blood of newborn piglets (Sus scrofa).] Avaliação imunofenotípica de subpopulações linfocitárias no sangue do cordão umbilical e periférico de suínos neonatos (Sus scrofa). Pesquisa Veterinária Brasileira 34(4):385-389. Departamento de Cirurgia e Anestesiologia Veterinária, Faculdade de Medicina Veterinária e Zootecnia, Universidade Estadual Paulista, Campus de Botucatu, Distrito de Rubião Júnior, s/n, Botucatu, SP 18618-970, Brazil. E-mail: ivansantos7@hotmail.com

Considering the importance of umbilical cord blood as a potential source of stem cell and, on the other hand, the use of the domestic swine (Sus scrofa) as a useful model for biomedical research in regenerative medicine and aiming to contribute about the quantification of lymphocyte subsets in umbilical cord blood and peripheral blood of newborn piglets, this study aimed to quantify $\mathrm{CD}^{+}, \mathrm{CD}^{+}$and $\mathrm{CD} 8^{+}$cells from umbilical cord blood and peripheral blood from pigs at term blood samples. Were analyzed samples of the umbilical cord blood and peripheral of 48 piglets of Topigs lineage, from healthy mothers, artificially inseminated and natural birth. Blood samples were collected from the umbilical cord at birth, by the umbilical vein, and peripheral blood by venous sinus retro-ophthalmic. The immunological measurements of $\mathrm{CD}^{+}, \mathrm{CD}^{+}$and $\mathrm{CD}^{+}$were obtained by flow cytometry. The relative average values for the $\mathrm{CD}^{+}, \mathrm{CD}^{+}$e $\mathrm{CD} 8^{+}$counts in umbilical cord blood and peripheral blood of newborn piglets were inferior to those reported for peripheral blood in adult pigs, suggesting immunological immaturity. The ratio $\mathrm{CD} 4^{+}: \mathrm{CD} 8^{+}$in umbilical cord blood $(3.2 \pm 1.2 \%)$ and peripheral blood $(3.2 \pm 1.7 \%)$ showed a predominance of TCD $4^{+}$over $\mathrm{TCD}^{+}$. The percentage of $\mathrm{CD}^{+}$and $\mathrm{CD}^{+}$cells was $1.37 \pm 0.86 \%$ and $1.15 \pm 0.57 \%$, respectively, in umbilical cord blood and peripheral blood.
\end{abstract}

INDEX TERMS: Cytometry, lymphocytes, pigs, immunophenotyping.

RESUMO.- Considerando a importância do uso do sangue do cordão umbilical como fonte potencial de células tronco hematopoiéticas e o uso do suíno doméstico (Sus scro$f a$ ) como modelo para pesquisas biomédicas em medicina

\footnotetext{
${ }^{1}$ Recebido em 23 de setembro de 2013.

Aceito para publicação em 20 de março de 2014.

${ }^{2}$ Pós-Graduanda em Medicina Veterinária, Departamento Clínica e Cirurgia Veterinária, Faculdade de Ciências Agrárias e Veterinárias (FCAV), Universidade Estadual Paulista (Unesp), Campus de Jaboticabal, Via de acesso Prof. Paulo Donato Castellane s/n, Jaboticabal, SP 14884-900, Brasil. Endereço permanente: Departamento de Clínica Veterinária, Faculdade de Veterinária, Universidade Eduardo Mondlane (UEM), Av. de Moçambique, Km 1,5, Maputo, Moçambique.

${ }^{3}$ Pós-Graduando em Medicina Veterinária, Departamento de Cirurgia e Anestesiologia Veterinária, Faculdade de Medicina Veterinária e Zootec-
}

regenerativa, e por outro lado, visando dar um contributo sobre a quantificação das subpopulações linfocitárias no sangue do cordão umbilical e periférico, objetivou-se quantificar as células $\mathrm{CD}^{+}, \mathrm{CD}^{+}$e $\mathrm{CD} 8^{+}$nas amostras de sangue

nia (FMVZ), Universidade Estadual Paulista (Unesp), Campus de Botucatu, Distrito de Rubião Júnior s/n, Botucatu, SP 18618-970, Brasil. *Autor para correspondência: ivansantos7@hotmail.com

${ }^{4}$ Pesquisadora do Institute of Orthopaedics and Musculoskeletal Science, University College of London (UCL), Brockley Hill, CEP: HA7 4LP, Stanmore, Middlessex, Reino Unido.

${ }^{5}$ Pós-Graduana da Faculdade de Zootecnia e Engenharia de Alimentos, Universidade de São Paulo, Av. Duque de Caxias Norte 225,CEP: 13635900, Pirassununga/SP, Brasil.

${ }^{6}$ Docente do Departamento de Clínica e Cirurgia Veterinária, FCAV-Unesp, Jaboticabal, SP. 
de suínos neonatos. Analisaram-se as amostras do sangue do cordão umbilical e periférico de 48 leitões de linhagem Topigs, provenientes de porcas hígidas, inseminadas artificialmente e de parto natural. Foram coletadas amostras de sangue do cordão umbilical e periférico no momento do nascimento, por meio de venopunção da veia umbilical e seio venoso retro-oftálmico, respectivamente. As quantificações imunofenotípicas de células $\mathrm{CD}^{+}, \mathrm{CD}^{+}$e $\mathrm{CD} 8^{+}$ foram obtidas por citometria de fluxo. Os valores médios obtidos para as contagens das células $\mathrm{CD}^{+}, \mathrm{CD}^{+}$e $\mathrm{CD} 8^{+}$do sangue do cordão umbilical e periférico apresentaram-se inferiores aos reportados para o sangue periférico de suínos adultos, sugerindo um componente imunológico imaturo. A proporção $\mathrm{CD} 4^{+}: \mathrm{CD} 8^{+}$obtida no sangue do cordão umbilical $(3,2 \pm 1,2 \%)$ e no sangue periférico $(3,2 \pm 1,7 \%)$ ilustrou a predominância dos linfócitos TCD $4^{+}$com relação aos TCD $8^{+}$. A quantidade relativa de células $\mathrm{CD} 4^{+}$e $\mathrm{CD} 8^{+}$no sangue do cordão umbilical e periférico foi de $1,37 \pm 0,86 \%$ e $1,15 \pm 0,57 \%$, respectivamente.

TERMOS DE INDEXAÇÃO: Citometria, linfócitos, suínos, imunofenotipagem.

\section{INTRODUÇÃO}

Durante as últimas três décadas, estudos sobre o sistema imunitário de suíno aumentaram significativamente, fase ao interesse pelo estudo do sistema linfoide. Este aumento foi devido à sua organização e a heterogeneidade única, associado à possibilidade de uso de suínos domésticos (Sus scrofa) como um modelo experimental promissor nas pesquisas em allo e xenotransplantes, devido a similaridade fisiológica ao homem (Sachs 1994, Cooper et al. 2002).

Por outro lado, o estudo sobre os anticorpos monoclonais específicos para as membranas de leucócitos de suíno, tornou possível, melhorando de certa forma, a caracterização do fenótipo e funções de várias populações de leucócitos desta espécie (Piriou-Guzylack \& Salmon 2008). Consequentemente, receptores de células T (TcR) de subconjuntos de células T- $\alpha \beta^{+}$e de células T- $\gamma \delta^{+}$, assim como os diferentes subconjuntos de células B, foram identificados no sangue periférico de suíno (Yang \& Parkhouse 1996), no baço, mesentério e sangue do cordão umbilical, entre o $40^{\circ}$ dia e $110^{\circ}$ dia de gestação (Sinkora et al. 1998).

Saalmuller et al. (1994), caracterizaram a molécula CD5+ e observaram que a mesma é expressa nos timócitos $(92 \%$ a $97 \%$ ) e em $54 \%$ a $97 \%$ nos linfócitos T do sangue periférico. Por outro lado, $10 \%$ a $30 \%$ dos linfócitos B expressam a molécula $\mathrm{CD}^{+}$em baixa intensidade. Dessa forma, altos níveis da molécula $\mathrm{CD}^{+}$são evidenciados nos linfócitos T auxiliares $\mathrm{CD}^{+}$, linfócitos T de memória CD4 e CD8 (duplo positivo) e em linfócitos T citotóxicos $\mathrm{CD}^{+}$(Piriou-Guzylack \& Salmon 2008).

O sistema imune de suíno apresenta certas particularidades, das quais é o único no qual a expressão de antígenos CD4 e CD8 definem quatro subpopulações de linfócitos T extra tímicos (Saalmuller et al. 1989). Além dos fenótipos clássicos dos linfócitos $\mathrm{CD}^{+}{ }^{+}$e CD8- (T auxiliares), e células CD4- e CD8+ (T citotóxicas), os linfócitos TCD4- e CD8, e $\mathrm{TCD}^{+}{ }^{+} \mathrm{CD} 8^{+}$, são predominantes na circulação, assim como no pool de linfócitos T tissulares (Saalmuller et al., 1989). Os mesmos podem ser encontrados entre o total dos linfócitos $\mathrm{T}$, sendo que $10 \%$ a $60 \%$ são células TCD4 ${ }^{+}$e TCD8 ${ }^{+}$ (Pescovitz et al. 1994). Zuckerman \& Husmann (1996) reportaram que este subconjunto de linfócitos T representa menos de $2 \%$ do total dos linfócitos em suínos com menos de uma semana de idade e aumenta gradualmente com a idade até 30 a $55 \%$ entre 45 e 54 meses de idades

Num estudo realizado por Sinkora et al. (1998), na qual pesquisaram o fenótipo de superfície das células linfoides fetais no timo, cordão umbilical, baço e no linfonodos mesentéricos, em diferentes estágios de gestação, observaram que o primeiro subconjunto de linfócitos TcR- $\alpha \beta^{+}$proeminentes, detectado no sangue do cordão umbilical foi o de linfócitos T auxiliares CD4 ${ }^{+}$e CD8 $\alpha \beta$. Os mesmos constituíram uma subpopulação de células T dominante ao longo de todo o desenvolvimento fetal, atingindo $30 \%$ de células positivas ao nascimento. Por outro lado, os linfócitos T citotóxicos CD4- e CD8 $\alpha \beta$ não foram identificados no cordão umbilical até aos 55 dias de gestação. Após este período, ocorreu um aumento gradativo até ao nascimento, atingindo os $10 \%$ ao $110^{\circ}$ dia de gestação.

A quantificação fenotípica de linfócitos do sangue do cordão umbilical pode ser realizada através da citometria de fluxo. As células são marcadas com anticorpos monoclonais específicos ligados aos fluorocromos, identificadas e quantificadas com base no seu tamanho, granularidade interna e intensidade de fluorescência (Roit et al. 2003).

Visto que o sangue do cordão umbilical constitui uma promissora fonte de células-tronco hematopoiéticas, representando superioridade em relação às outras fontes, principalmente no que se refere à facilidade de coleta, quantidade e qualidade celular e menor incidência de reações imunes após transplantes, devido à imaturidade dos linfócitos T (Rocha et al. 2001, Rogers \& Casper 2004), o estudo tem como objetivo avaliar quantificamente as células linfocitárias $\mathrm{CD}^{+}, \mathrm{CD}^{+}{ }^{+}$e $\mathrm{CD}^{+}$no sangue do cordão umbilical de suínos neonatos, utilizando anticorpos monoclonais específicos para cada tipo celular, e deste modo fornecer informação relativa à composição de células do sangue do cordão umbilical de suínos neonatos e comparar com os valores obtidos do sangue periférico.

\section{MATERIAL E MÉTODOS}

Foram utilizados 48 leitões de linhagem Topigs, provenientes de porcas hígidas, inseminadas artificialmente e de parto natural. Sangue do cordão umbilical $(6 \mathrm{~mL})$ foi coletado no momento do nascimento, por venopunção da veia umbilical, na porção justa placentária do cordão umbilical. Após a coleta, as amostras foram colocadas em tubos contendo ácido etilenodiamninotetracético dipotássico ( $\mathrm{K}_{2}$ - EDTA), em solução aquosa a 10\%. Em seguida, foi coletado de cada leitão sangue periférico $(2 \mathrm{~mL})$, por venopunção no seio venoso retro-oftálmico, e colocados tubos contendo ácido etilenodiamninotetracético dipotássico ( $\mathrm{K}_{2}$ - EDTA), em solução aquosa a $10 \%$.

Após as coletas, as amostras foram mantidas refrigeradas, por um período de três horas, antes da realização dos exames laboratoriais. As amostras do sangue do cordão umbilical e do periférico foram submetidas à contagem total dos leucócitos, utilizando um contador automático de células (ABC-VET, ABX - Fr), e a contagem 
diferencial foi realizada por meio de esfregaços de sangue, fixados ao ar e imediatamente corados com uma mistura de Metanol, May-Grünwald e Giemsa.

Para a avaliação citofluorométrica, as amostras foram preparadas 24 horas após a coleta, sendo o procedimento realizado no Laboratório de Patologia Clínica Veterinária, Faculdade de Ciências Agrárias e Veterinárias de Jaboticabal, Unesp.

Foram utilizados cinco tubos cônicos Falcon para cada amostra de sangue do cordão umbilical e periférico, colocando $100 \mu \mathrm{L}$ da amostra de sangue correspondente.

No tubo 1 (controle negativo celular) não foi adicionada nenhuma substância. No tubo 2 (controle negativo isótopo), foram adicionados $2 \mu \mathrm{L}$ dos isótopos IgG2b Alexa fluor 488 (MCA691 A488, AbDSerotec, Bio-Rad Laboratories, Inc, USA) e IgG2a PE (MCA929PE, AbD Serotec, Bio-Rad Laboratories, Inc., USA).

No tubo 3 (imunomarcaçao direta para $C D 4^{+}$e $C D 8^{+}$) foram adicionados os anticorpos monoclonais camundongo anti-suíno CD4a FITC (clone MIL17, MCA1749F, AbDSerotec, Bio-Rad Laboratories, Inc, USA) e W CD8a RPE (clone MIL-12MCA1223PE, AbD Serotec, Bio-Rad Laboratories, Inc, USA). No tubo 4 (controle negativo do anticorpo secundário) adicionou-se $0,5 \mu \mathrm{L}$ do anticorpo secundário Goat anti-mouse conjugado ao fluorocromo Alexa Fluor 647 (Bio-Rad Laboratories, Inc., USA).

Finalmente, no tubo 5 (imunomarcação indireta para $\mathrm{CD}^{+}$) foram adicionados $2 \mu \mathrm{L}$ de anticorpo monoclonal camundongo anti-suíno CD5 purificado (clone 1H6/8, MCA2307, AbDSerotec, Bio-Rad Laboratories, Inc., USA).

Todos os tubos foram submetidos à incubação em temperatura ambiente e no escuro por 20 minutos. Em seguida, foram adicionados $1 \mathrm{~mL}$ de tampão de lise de hemácias (FACS Lysing Solution,Becton Dickinson, USA) aos tubos 1, 2, 3 e 4, seguido de homogeneização, e novamente incubados na ausência de luz por 10 minutos, à temperatura ambiente. A suspensão de células foi submetida a centrifugação a 1800 rpm por 3 minutos e o sobrenadante foi descartado. De seguida, foram adicionados $2 \mathrm{~mL}$ de solução salina tamponada com fosfato $0,01 \mathrm{M}$ e pH entre 7,4 e 7,6 (PBS). Este procedimento foi repetido por duas vezes.

No tubo 5, após a primeira incubação, foi realizada uma lavagem com PBS e a suspensão celular foi centrifugada à 1800 rpm por 3 minutos e o sobrenadante foi descartado. Após a centrifugação foi adicionado $0,5 \mu \mathrm{L}$ de anticorpo secundário Goat anti-mouse conjugado com fluorocromo Alexa Fluor 647 (Bio-Rad Laboratories, Inc, USA) e submetido à incubação no escuro, em temperatura ambiente, por 20 minutos. De seguida, foi adicionado $1 \mathrm{~mL}$ de tampão de lise hemácias (FACS Lysing Solution,Becton Dickinson, USA) e resubmetido à incubação por mais 10 minutos, desprovido de luz e em temperatura ambiente. Uma segunda centrifugação foi realizada a 1800 rpm por 3 minutos, e o sobrenadante foi descartado. Adicionou-se $2 \mathrm{~mL}$ de PBS e realizou-se os procedimentos de lavagem das células novamente. Este procedimento foi repetido por duas vezes. Após a última lavagem, as células foram suspendidas com $100 \mu \mathrm{L}$ de PBS, em formol a $1 \%$.

As amostras foram submetidas à análise no citofluorômetro (FACS Calibur, Becton Dickinson, USA) para identificação e contagem das células $\mathrm{CD}^{+}, \mathrm{CD}^{+}$e $\mathrm{CD} 8^{+}$. Para a identificação e quantificação das populações das células $\mathrm{CD}^{+}, \mathrm{CD}^{+}$e $\mathrm{CD} 8^{+}$, foram obtidos 10000 eventos utilizando o programa de computador (Cell Quest Pro Software, Becton Dickinson, USA), que forneceu o histograma e tabela com a quantidade de células positivas detectadas pela imunofenotipagem.

0 cálculo dos valores absolutos de células $\mathrm{CD}^{+}, \mathrm{CD}^{+}$e $\mathrm{CD}^{+}$ no sangue do cordão umbilical e periférico foi realizado multiplicando o número de eventos (células positivas para $\mathrm{CD} 4^{+}, \mathrm{CD}^{+} \mathrm{e}$
$\mathrm{CD}^{+}$no citômetro de fluxo) pela contagem absoluta de linfócitos e dividido por 100 .

Para a comparação dados da contagem de células $\mathrm{CD} 4^{+}, \mathrm{CD}^{+} \mathrm{e}$ $\mathrm{CD}^{+}$, entre os grupos sangue do cordão umbilical e periférico, foi utilizado o teste $\mathrm{T}$ pareado com $\mathrm{P}<0,05$ considerado significativo.

0 trabalho foi aprovado pela comissão de Ética no uso de animais da Faculdade de Ciências Agrárias e Veterinárias de Jaboticabal, Unesp (Protocolo no 012421/10).

\section{RESULTADOS}

Os valores do leucograma foram usados para o cálculo do valor absoluto das subpopulações linfocitárias, sendo que os valores médios e desvios padrões obtidos para contagem total dos leucócitos no sangue do cordão umbilical e periférico, ao nascimento, foram: $4,84 \pm 1,57.10^{3}$ leucócitos $/ \mu \mathrm{L}$ e $6,98 \pm 2,5.10^{3}$ leucócitos $/ \mu \mathrm{L}$, respectivamente. Em relação aos linfócitos, os valores médios e desvios padrões no sangue do cordão umbilical e periférico, ao nascimento, foram:

Quadro 1. Valores relativos médios (\%) e desvios padrões de células CD4+, CD5+ e CD8+ do sangue do cordão umbilical (SCU) e periférico (SP), coletado imediatamente após o nascimento de suínos neonatos $(\mathrm{n}=48)$. Jaboticabal/SP, 2011

\begin{tabular}{lccr}
\hline Grupos & CD4+\% & CD5+\% & \multicolumn{1}{c}{ CD8+\% } \\
\hline SCU & $31,48 \pm 8,8 \mathrm{~A}$ & $55,08 \pm 19,72 \mathrm{~A}$ & $10,6 \pm 3,2 \mathrm{~A}$ \\
SP & $30,85 \pm 7,9 \mathrm{~A}$ & $56,34 \pm 17,13 \mathrm{~A}$ & $11,13 \pm 4,2 \mathrm{~A}$
\end{tabular}

Médias da mesma coluna, seguidas por letras maiúsculas iguais, não diferem entre si $(\mathrm{P}<0,05)$ e estabelecem a comparação entre os grupos.

Quadro 2. Valores absolutos médios (células $/ \mu \mathrm{L}$ ) e desvios padrões de células CD4+, CD5+ e CD8+ do sangue do cordão umbilical (SCU) e periférico (SP), coletado imediatamente após o nascimento de suínos neonatos $(\mathrm{n}=48)$. Jaboticabal/ SP, 2011

\begin{tabular}{lccc}
\hline Grupos & $\begin{array}{c}\text { CD4+ } \\
\text { (células/ } \mu \mathrm{L} \text { ) }\end{array}$ & $\begin{array}{c}\text { CD5+ } \\
\text { (células } / \mu \mathrm{L} \text { ) }\end{array}$ & $\begin{array}{c}\text { CD8+ } \\
\text { (células } / \mu \mathrm{L} \text { ) }\end{array}$ \\
\hline SCU & $455,3 \pm 198,9 \mathrm{~A}$ & $812,7 \pm 434,7 \mathrm{~A}$ & $154,8 \pm 76,3 \mathrm{~A}$ \\
SP & $597,4 \pm 324,8 \mathrm{~A}$ & $1066,1 \pm 586,8 \mathrm{~A}$ & $211,7 \pm 121,2 \mathrm{~A}$
\end{tabular}

Médias da mesma coluna, seguidas por letras maiúsculas iguais, não diferem entre si $(\mathrm{P}<0,05)$ e estabelecem a comparação entre os grupos.

$1,54 \pm 0,74.10^{3}$ linfócitos $/ \mu \mathrm{L}$ e $1,91 \pm 0,84.10^{3}$ linfócitos $/ \mu \mathrm{L}$, respectivamente. Os valores médios relativos e absolutos e os respectivos desvios padrões da contagem de células CD4 ${ }^{+}$, $\mathrm{CD}^{+}$e $\mathrm{CD}^{+}$no sangue do cordão umbilical e periférico de suínos neonatos, estão apresentados nos Quadros 1 e 2.

A razão CD4/CD8 (duplo positivo) no presente estudo foi de 3,2 , tanto para o sangue do cordão umbilical como para o sangue periférico, indicando que as células $C D 4^{+}$representam o subconjunto de células dominantes quando comparadas com as $\mathrm{CD}^{+}$. Em relação ao sangue do cordão umbilical, obteve-se um valor relativo de $31 \%$ para as células $\mathrm{CD}^{+}$, e $10,6 \%$ para as $\mathrm{CD}^{+}$, e no sangue periférico os valores relativos foram de $30,8 \%$ e $11,1 \%$, de $C D 4^{+}$e CD8 ${ }^{+}$, respectivamente.

Relativamente aos linfócitos $\mathrm{TCD}^{+}$, os valores relativos obtidos do sangue do cordão umbilical e periférico foram $56,2 \%$ e 56,5\%. O subconjunto de linfócitos TCD4+ e TCD8 ${ }^{+}$, apresentaram valores de 1,3\% e 1,1\% no sangue do cordão umbilical e periférico, respectivamente. 


\section{DISCUSSÃO}

Os leitões, diferentemente dos suínos adultos, constituem uma fonte única de material para estudo do desenvolvimento da resposta imune pós-nascimento sem qualquer outro estímulo de antígeno, desde que sejam criados livres de germes e com ambiente livre de antígenos (Lunney et al. 2002).

Embora existam relatos de imunofenotipagem de linfócitos do sangue de suínos em diferentes faixas etárias (Pescovitz et al. 1985, Joling et al. 1994, Saalmuller et al. 1994), estudos publicados em relação as características imunofenotípicas do sangue do cordão umbilical e periférico em suínos neonatos são escassos. Sendo assim, este estudo fornece informações para o ponto de partida de futuros estudos com sangue de cordão umbilical de suínos.

Os anticorpos monoclonais CD4, CD5 e CD8, usados no estudo, foram selecionados conforme descrito por Pescovitz et al. (1985) e caracterizados durante o primeiro e segundo Workshop Internacional Suíno (Lunney et al. 1994). Segundo Byrne et al. (2000), a análise dos linfócitos pela citometria de fluxo deve ser precedida pela contagem total e diferencial dos leucócitos. Os valores absolutos para as diferentes subpopulações linfocitárias são estabelecidos com base nas porcentagens obtidas por citometria de fluxo, nos valores totais de leucócitos e relativos de linfócitos, sendo assim foi realizado o leucograma para o cálculo do valor absoluto das subpopulações linfocitárias.

A razão CD4/CD8 (duplo positivo) de 3,2, tanto para o sangue do cordão umbilical como para o sangue periférico, indicou que as células $\mathrm{CD} 4^{+}$representaram o subconjunto de células dominantes quando comparadas com as $\mathrm{CD}^{+}$, sendo coerente com o citado por Sinkora et al. (1998) no sangue do cordão umbilical de suínos no período entre o $55^{\circ}$ dia e $110^{\circ}$ dia de gestação. Schultz et al. (2000), em um estudo realizado com imunohematologia humana, considerou a dominância de linfócitos TCD $4^{+}$em fetos como reflexo de um mecanismo fisiológico que visa prevenir uma possível rejeição fetal.

As porcentagens médias obtidas no estudo em relação ao sangue do cordão umbilical e periférico para as células $\mathrm{CD}^{+}$e $\mathrm{CD}^{+}$, foram relativamente mais baixas quando comparadas às obtidas por Pescovitz et al. (1994), Whittall \& Parkhouse (1997) no sangue periférico de suínos adultos. Essa diferença pode ser explicada pelo fato que após o parto, os neonatos possuindo um sistema imune imaturo e sem contato prévio com antígenos, são expostos a um ambiente não estéril, induzindo uma resposta imunitária primária mais baixa e menos diversificada em relação aos suínos adultos (Salmon 2000). Estudos realizados por Sinkora et al. (1998) observaram ao longo do desenvolvimento fetal de suínos um aumento gradual de células $\mathrm{CD}^{+}$e $\mathrm{CD}^{+}$, chegando aos $110^{\circ}$ dia de gestação com valores de 30\% e 10\% para $\mathrm{CD}^{+}{ }^{+} \mathrm{CD}^{+}$, respectivamente. Esses valores são inferiores aos obtidos no presente estudo, tanto para o sangue do cordão umbilical quanto para o periférico, sendo observado, mais claramente, nos valores absolutos.

Relativamente aos linfócitos TCD5+, os valores relativos obtidos do sangue do cordão umbilical $(56,2 \%)$ e periférico (56,5\%), são similares aos relatos por Li \& Chen (2001), Tizzard (2002), porém, em suínos adultos.
Os resultados obtidos no estudo revelaram uma quantidade total de células T e de subpopulações linfocitárias do sangue do cordão umbilical e periférico de suínos neonatos menor que a quantidade relatada por Godoy et al. (2007) em equinos e Cápua et al., (2009) em caninos. Essa menor quantidade de células $\mathrm{T}$ observadas no sangue do cordão umbilical sugere um componente imunológico imaturo, e pode ser explicado pela expressão tardia de moléculas de superfície após o nascimento (Schultz et al. 2000).

No estudo, obteve-se um subconjunto de linfócitos $\mathrm{TCD}^{+}{ }^{+}$e $\mathrm{TCD}^{+}$no sangue do cordão umbilical e periférico e valores similares aos relatados por Zuckermann et al. (1990), na qual obtiveram valores menores que $2 \%$, no sangue periférico de suínos com uma semana de idade. De acordo com Pescovitz et al. (1985), Joling et al. (1994), um número considerável deste subconjunto de células é detectado no baço e no sangue periférico. Em outras espécies, presume-se que estas células desintegram-se no timo ou se diferenciam em $\mathrm{CD}^{+}{ }^{+} \mathrm{CD}^{-}$ou $\mathrm{CD}^{-} \mathrm{CD}^{+}$ao longo do tempo (Scollay \& Shortman 1985). Contudo, os suínos são uma exceção, devido à detecção de $\mathrm{CD}^{+}{ }^{+}$e $\mathrm{CD}^{+}$no sangue e no baço, também, nos linfonodos de suínos adultos, sendo a sua função desconhecida (Zuckerman \& Husmann 1996). Contudo, Tizard (2002) sugeriu que essa população de linfócitos $\mathrm{T}$, duplamente positivos, pertence às células T efetoras de memória.

\section{CONCLUSÕES}

A quantidade de linfócitos $\mathrm{T} \mathrm{CD5}^{+}$(Pan-T) e subpopulações linfocitárias CD4+ (T auxiliares) e CD8+ (T citotóxicas) do sangue do cordão umbilical não difere do sangue periférico obtido do seio venoso retro-oftálmico de suínos neonatos; porém, se mostra inferior à reportada para o sangue periférico de suínos adultos, sugerindo um componente imunológico imaturo.

A razão CD4/CD8 (duplo positivo) possui predominância de células $\mathrm{CD}^{+}$, estando presente, tanto no sangue do cordão umbilical como no sangue periférico de suínos neonatos, uma porcentagem de células $\mathrm{CD}^{+}{ }^{+} \mathrm{CD} 8^{+}$menor que $1,5 \%$.

Agradecimentos.- À Fundação de Amparo à Pesquisa do Estado de São Paulo (FAPESP, Proc. 2010/16569-4).

\section{REFERÊNCIAS}

Cápua M., Santana A.E., Nakage A.M., Godoy A.V. \& Kataoka A. 2009. Subpopulações de linfócitos T no sangue de cordão umbilical de cães. Arq. Bras. Med. Vet. Zootec. 61:791-796.

Cooper D.K., Gollackner B. \& Sachs H.H. 2002. Will the pig solve the transplantation backlog? Annu. Rev. Med. 53:133-147.

Godoy R.F., Santana A.E., Palma P.B., Rossetto F. \& Oliveira J.V. 2007. Quantificação de subpopulações linfocitárias no sangue do cordão umbilical de equinos. Ciência Rural 37(3):734-739.

Joling P., Bianchi A.T.J., Kappe A.L. \& Zwart R.J. 1994. Distribution of lymphocyte subpopulation in Thymus, spleen and peripheral blood of specific pathogen free pigs from 1 to 40 weeks of age. Vet. Immun. Immunopathol. 40:105-117.

Li H. \& Chen Y. 2001. Phenotypic and functional analysis of porcine T lymphocytes. Tsinghua Science and Techonology 6(3):273-276.

Lunney J.K., Walker K. \& Goldman T. 1994. Overview of the first interna- 
tional workshop to define swine leukocyte cluster of differentiation (CD) antigens. Vet. Immunol. Immunopathol. 43:193.

Lunney J.K., Fossum C., Alm G.V., Steinbach F. \& Wattrang E. 2002. Veterinary immunology: opportunities and challenges. Trends Immunol. 23:4-6.

Pescovitz M.D., Lunney J.K. \& Sachs D.H. 1985. Murine anti-swine T4 and T8 monoclonal antibodies: distribution and effects on proliferative and cytotoxic T cells. J. Immunol. 134:37-44.

Pescovitz M.D., Sakopoulos A.G., Gaddy J.A., Husmann R.J. \& Zuckermann F.A. 1994. Porcine peripheral blood $\mathrm{CD}^{+} / \mathrm{CD}^{+}$dual expressing Tcells. Vet. Immunol. Immunopathol. 43:53-62.

Piriou-Guzylack L. \& Salmon H. 2008. Membrane Markers of the immune cells in swine: an update. Vet. Res. 39:54.

Roger S.I. \& Casper R.F. 2004. Umbilical cord blood stem cells. Clin. Obstet. Gynaecol. 18:893-908.

Rocha V., Carmagnatb M.V., Chevretc S., Flinoisb O., Bittencourta H., Esperoua H., Garniera F., Ribauda P., Devergiea A., Sociéa G., Dal'Cortivod L., Marolleaud J.P., Charronb D., Gluckmana E. \& Rabian C. 2001. Influence of bone marrow graft lymphocyte subsets on outcome after HLA identical sibling transplants. Exp. Hematol. 29(11):1347-1352.

Roitt I., Brostoff J. \& Male P. 2003. Imunologia. 7aㅡ ed. Manole, São Paulo. 481p.

Saalmuller A., Hirt W. \& Reddehase M.J. 1989. Phenotypic discrimination between thymic and extrathymic CD $4-\mathrm{CD} 8-$ and $\mathrm{CD} 4^{+} \mathrm{CD} 8^{+}$porcine $\mathrm{T}$ lymphocytes. Eur. J. Immunol. 19:2011.

Saalmuller A., Hirt W. \& Maurer S. 1994. Discrimination between two subsets of porcine $\mathrm{CD}^{+}$cytolytic $\mathrm{T}$ lymphocytes by the expression of CD5 antigen. Immunology 81:578-583.
Sachs D.H. 1994. The pig as a potential xenograft donor. Vet. Immunol. Immunopath. 43:185.

Salmon H. 2000. Mammary gland immunology and neonate protection in pigs. Homing of lymphocytes into the MG. Adv. Exp. Med. Biol. 480:279286.

Schultz C., Reiss I. \& Bucsky P. 2000. Maturational changes of lymphocyte surface antigens in human blood: Comparison between fetuses, neonates and adults. Biol. Neonate 78:77-82.

Scollay R. \& Shortman K. 1985. Identification of early stages of T lymphocyte development in the thymus cortex and medulla. J. Immunol. 134(6):3632-3642.

Sinkora M., Sinkora J. \& Rehaková Z. 1998. Prenatal ontogeny of lynphocyte subpopulations in pigs. Immunology 95:595-603.

Tizard I.R. 2002. Imunologia Veterinária: uma introdução. Roca, São Paulo, p.76-105.

Whittall J.T.D. \& Parkhouse R.E. 1997. Monoclonal antibodies defining differentiation antigens of swine lymphoid and myeloid cells. Vet. Immunol. Immunopathol. 60:149-160.

Yang H. \& Parkhouse R.M. 1996. Phenotypic classification of porcine lymphocyte subpopulations in blood and lymphoid tissues. Immunology 89:76.

Zuckermman F.A. \& Husmann R.J. 1996. Functional analysis of porcine peripheral blood CD4/CD8 double-positive T cells. Immunology 87:500512.

Zuckermann F.A., Zsak L., Mettenleiter T.C. \& Ben-Porat T. 1990. Pseudorabies virus glycoprotein gIII is a major target antigen for murine and swine virus-specific cytotoxic T lymphocytes. J. Virol. 64:802. 